\section{Doing the rounds of the Solar System}

\author{
Carl D. Murray
}

Rings: Discoveries from Galileo to

Voyager.

By James Elliot and Richard Kerr.

MIT Press:1985. Pp.209.

$\$ 17.50, £ 19.50$.

OBSERVATIONS of the occultation of star SOA 158687 by the planet Uranus on 10 March, 1977, were intended to provide information on the shape and atmosphere of Uranus. An unexpected bonus for Jim Elliot and his team in the Kuiper Airborne Observatory was the first discovery of a ring system since the time of Galileo. After more occultations, the spectacular successes of the Pioneer and Voyager spacecraft and the increased use of charge coupled devices (CCDs), astronomers now have the luxury of studying planetary rings on a comparative basis.

Even to document the recent discoveries and theories is a difficult task after such an influx of ground-based and spacecraft results. But the authors of this book do not merely present the observations together with the latest well-polished theories, they also treat the reader to a revealing and honest portrayal of scientific discovery, complete with rejected grant applications, rivalry and occasional good luck.

In particular, the account of the spacecraft flybys captures the unique atmosphere of "instant science", when making discoveries "is just a matter of who's around". Explaining them can take a little longer. Theorists have had to turn their attention to such phenomena as narrow rings, eccentric rings, multiple rings and "spokes". The book relates how, during the Voyager 1 encounter with Saturn, some of the best theorists were unable to explain the "braided" appearance of Saturn's F-ring. Although there were doubts that gravitational forces alone could account for such a feature, one of the faithful remarked, "Don't worry about Newton's equations, most people don't realize how many solutions they have". Current theories of the F-ring have shown that his faith in gravity was not misplaced.

Accounting for some features can lead to more fundamental problems. Studies of satellite-ring interactions and the identification of spiral density waves have provided an explanation for most of the structure in Saturn's A-ring. However, the same studies reveal the possibility that unless some locking mechanism can be found we may have to come to terms with the fact that the rings are relatively shortlived phenomena.

The combination of first-hand experience and good journalism has resulted in an immensely readable account of how ring studies have evolved over the past three centuries. Glimpses of the personalities involved and clear explanations of the various physical processes and ring theories help to convey the excitement of science. This golden age of discovery is not over. In January 1986 we can expect images of the Uranian rings from Voyager 2. Before the end of the decade we will have further information on the peculiar

\section{Levels of dispute}

\section{Paul Hoyningen-Huene}

Science and Values: The Aims of Science and Their Role in Scientific Debate.

By Larry Laudan.

University of California Press: 1984.

Pp.149.\$15, £14.25.

SCIENCE, viewed as a social enterprise, has two complementary features: the formation of agreement from disagreement and the formation of disagreement from agreement. The task of explaining these features was made prominent more than 20 years ago by Thomas S. Kuhn in his Structure of Scientific Revolutions. Laudan takes up the subject once more, thus putting himself in competition with Kuhn and many other writers. Before addressing the resulting quarrels, we should look at the model that Laudan proposes.

Laudan distinguishes three levels of scientific commitment on which agreement or disagreement occurs: a "factual level", concerning claims about the world; a "methodological level", concerning claims about the correct way of doing science; and an "axiological level", concerning the basic cognitive aims of science (that is, those properties of theories that are constitutive of good theories). Traditionally, the interaction between these levels is seen as follows: disagreement on the factual level can be rationally resolved by recourse to the methodological level, and disagreement on the methodological level by recourse to the axiological level. The second of these steps is possible since methodological rules are instruments for realizing cognitive goals. The obvious difficulty which this hierarchical dependence of levels leaves unresolved is that disagreement on the axiological level cannot be eliminated.

Laudan adds more interactions to the traditional hierarchical dependence of the levels, resulting in what he calls the "reticulated model". In this model, the methodological level is also influenced by the factual level. Scientific methods can and must, he says, be judged also with respect to the factual level: what is already known about a subject matter obviously influences the choice of subsequent scientific methods. Second, the axiological level is ๑) 1985 Nature Publishing Group rings or arcs of material around Neptune and a look at Jupiter's ring from the Galileo spacecraft. There will be more discoveries, more puzzled astronomers, more theories and, we must hope, an equally fascinating sequel to this splendid book.

Carl D. Murray is a Lecturer in the Theoretical Astronomy Unit at Queen Mary College, University of London.

connected to the other levels by feedback loops that sometimes allow for rational resolution of axiological disagreement. Explicit cognitive values - value statements - may, according to Laudan, rationally be criticized for being "utopian", that is for being incapable of application, or for not being consonant with shared exemplary scientific work. (At this point, however, Laudan appears to confound explicit value declarations with values displayed in actual scientific practice.) The interdependence of the different levels in the reticulated model permits rational transitions between many of the eight combinatorially possible states of threelevel agreement-disagreement.

Laudan's development of the model is accompanied by attacks on other writers in the field. Correspondingly, he declares his book to be a contribution to the "decanonization of a discipline's patron saints" (xiii), and his principal target throughout is T.S. Kuhn. But the creature decanonized by Laudan is largely a product of his own imagination. For example, a central sin that Laudan identifies in Kuhn's work is what he calls "the covariance fallacy", the assertion of a rigid bond between changes on the factual and on the axiological level (43ff.). But Kuhn, in an article that Laudan repeatedly cites, has described at length a very different sort of association, one that invokes just the sort of delayed feedback loop that Laudan takes to be his own. Elsewhere, documenting Kuhn's distrust of rationality, Laudan attributes to him the view "that it was perfectly reasonable for Priestley to hold onto phlogiston theory" (pp.72-73, my italics). But what Kuhn said in the relevant passage is the reverse: "the historian can always find men - Priestley, for instance - who were unreasonable to resist for as long as they did" (Structure, p.159, my italics). These examples stand for a host of others. Scholarly debate should not be conducted in this way.

Paul Hoyningen-Huene, currently a Visiting Scholar at the Massachusetts Institute of Technology, is a Lecturer in Philosophy of Science at the Universities of Bern and Zürich.

The most recent volume to appear in Pergamon's Key Environments series is Antarctica, edited by W.N. Bonner and D.W.H. Walton. Price is $£ 14.95, \$ 23.95$. For review of the first three volumes see Nature 312, 205 (1984). 